\title{
Novel zeolite Na-X synthesized from fly ash as a heterogeneous catalyst in biodiesel production
}

Omotola Babajide*, Nicholas Musyoka, Leslie Petrik, Farouk Ameer

Environmental and Nano Sciences Group, Chemistry Department, University of the Western Cape, Private Bag X17, Bellville 7535, South Africa

* Corresponding author at: Environmental and Nano Sciences Group, Chemistry Department, University of the Western Cape. E-mail address: obabajide@uwc.ac.za (O. Babajide).

\begin{abstract}
Several studies have been carried out on the production of biodiesel using different heterogeneous catalysts but this study has been able to demonstrate the prospect of utilizing South African class F fly ash as a raw material for zeolite synthesis subsequently applied as a solid base catalyst in the production of biodiesel. A novel faujasite zeolite material synthesized from South African class $F$ fly ash and denoted as FA/Na-X was ion exchanged with potassium to obtain the South African class F fly ash based zeolite FA/K-X. This heterogeneous catalyst was used in the conversion of sunflower oil with methanol to yield fatty acid methyl esters. Different characterization techniques were employed to give more information about this zeolite material. The FA/Na-X and the ion exchanged FA/K-X were applied as catalysts in biodiesel synthesis via transesterification reactions. A high quality biodiesel with a yield of $83.53 \%$ was obtained at reaction conditions of methanol:oil ratio of $6: 1$, catalyst amount of $3 \%(\mathrm{w} / \mathrm{w})$ of oil and reaction temperature of $65^{\circ} \mathrm{C}$ after $8 \mathrm{~h}$.
\end{abstract}

Keywords: Zeolite, Fly ash, Heterogeneous catalyst, FAME, Biodiesel

\section{Introduction}

Biodiesel is a green fuel considered a potential substitute of conventional diesel. It has been proved to be biodegradable, renewable and offer reduced emissions of $\mathrm{CO}_{2}, \mathrm{SO}_{2}$ particulates and hydrocarbons compared to fossil diesel [1]. Biodiesel comprises of mono-alkyl esters of long chain fatty acids derived from fatty acid triglycerides via transesterification reactions. Transesterification of oil/fat can be catalysed by alkalis [2], acids [3] or enzymes [4]. Amongst alkali and acid-catalysed transesterification; the reaction is much slower with acid catalysts [3]. Moreover, the corrosive acid-catalysed transesterification needs extreme temperature and pressure conditions. Although the catalytic activity of a base is higher than that of acid, use of the homogeneous base catalyst is not practical because of various issues such as catalyst removal after the reaction, substantially lower ester yield and 
difficulty in product separation, and thus recent research has focused on the use of heterogeneous catalysts in the conversion of triglycerides into methyl esters [5]. The use of the solid base catalysts possesses potential for new developments in the production of biodiesel; allowing process simplification and offering reduction in processing costs by improving the mass transfer limitation of the three phase reaction and simplifying the product purification processes compared to what is required in conventional homogeneous catalysis.

Coal fly ash (FA) is an inorganic residue and a waste product arising from the coal combustion processes in coal-fired power stations. The global annual production of FA is about 800 million tons and this amount has been predicted to increase in the future [6]. The management of fly ash waste poses important challenges as its global recycling rate is only $15 \%$ at present, making the efficient disposal of FA a worldwide issue because of its massive production and its harmful effects on the environment [7]. Fly ash is an agglomerate of microspheres, which are mainly composed of $\mathrm{Si}$ and $\mathrm{Al}$ with minor amounts of $\mathrm{Fe}, \mathrm{Na}, \mathrm{K}, \mathrm{Ca}, \mathrm{P}, \mathrm{Ti}$, and $\mathrm{S}$. The major mineral compound is amorphous aluminosilicate (glass) but other crystalline minerals are also present, such as mullite, quartz, hematite, magnetite, lime, anhydrites, and feldspars [8]. These chemical, mineralogical, and textural features make fly ash a highly suitable starting material for zeolite synthesis. The conversion of fly ash into zeolite not only eliminates the disposal problem but also turns an otherwise waste material into a useful one. Several studies have successfully prepared zeolites from fly ash under different reaction conditions [9-12]. Potential applications for synthesized fly ash zeolites include their use as molecular sieves, catalysts, ion exchangers [12] and also for the prevention of contamination of ground water, treatment of acid mine drainage and for $\mathrm{CO}_{2}$ adsorption [10,13,14]. Zeolites $\mathrm{X}$ modified by alkali ion exchange has emerged as an appealing solid base in biodiesel synthesis since relatively weak basic sites and strong basic sites can be produced via alkali metal ion exchange and impregnation of basic components respectively [15-18]. It has been reported that the ion exchange of zeolite $\mathrm{Na}-\mathrm{X}$ with larger monovalent cations such as $\mathrm{K}^{+}$and $\mathrm{Cs}^{+}$ clearly increases its basic strength $[15,16]$. Ion exchange with $\mathrm{K}^{+}$is more effective than with other alkali earth metals, in terms of the basicity and transesterification activity, because the size of the larger ions limits the exchange capacity compared to that for the smaller ions, affecting the basicity associated with the framework oxygen [15]. The chemical composition, pore size distribution and ion exchange properties of zeolite are responsible for their versa- tile catalytic behaviour [10,11]. In a previous study by the authors, South African Class F fly ash loaded with potassium was used as a solid-base catalyst in the transesterification of sunflower oil to methyl esters to make a meaningful utilization of waste coal fly ash in biodiesel catalysis [19]. With the cost of synthesizing zeolite X from coal fly ash estimated to be almost one-fifth of that of producing commercial zeolites [7], the applications of the fly ash based hierarchical zeolites in biodiesel production is expected to be a low cost substitute for the commercially available zeolite $\mathrm{X}$ synthesized using conventional feedstocks. The use of the fly ash derived zeolite will 
not only generate more revenue for the coal combustion power plants but will also reduce the costs associated with disposal of the fly ash. This subsequent paper gives an overview of the synthesis of a zeolite Na-X zeolite utilizing the same South African Class F fly ash as a feedstock. The application of other types of zeolite in biodiesel production has also been reported [20,21]. To the best of our knowledge, no report of a fly ash derived zeolite $\mathrm{Na}-\mathrm{X}$ used as a catalyst in biodiesel synthesis has been reported in literature. We report the application of the synthesized Na-X zeolite from Arnot fly ash (FA/Na-X), ion exchanged with K (FA/K-X) as heterogeneous catalysts in the production of biodiesel.

\section{Experimental methods}

\subsection{Oil characterization of vegetable oil}

The sunflower oil used in this study was obtained from a local supplier (Cape Town, South Africa). The fatty acid composition was determined by Gas Chromatography (AOCS 1-62), density at $15{ }^{\circ} \mathrm{C}$ (standard method EN ISO 3675), acid value (standard method ISO 1242:1999) and moisture content (standard method EN ISO 12937). Viscosity was determined using an Anton Parr Physica MCR 501 Rheometer. Methanol (Merck chemicals), TLC spray reagent; phosphomolybdic acid (Sigma Aldrich), ethanol (99.9\%), acetic acid (99.9\%), ethyl acetate (99.9\%) and hexane (99.9\%) were all purchased from Merck Chemicals, South Africa.

\subsection{Catalyst preparation}

The main raw material, waste coal fly ash, was collected from a South African coal power plant to synthesize the fly ash derived zeolite FA/Na-X catalyst. The fly ash derived zeolite FA/Na-X catalyst was prepared according to the conventional hydrothermal synthesis process procedure [23]. The synthesized zeolite FA/Na-X was then modified by an ion exchange process with an alkali metal $\left(\mathrm{K}^{+}\right)$using potassium acetate as a precursor. The $\mathrm{FA} / \mathrm{Na}-\mathrm{X}$ was dried in the oven at $110^{\circ} \mathrm{C}$ for $2 \mathrm{~h}$ to remove any water on its surface, and then dispersed in a 1.0 $\mathrm{M}$ solution of potassium acetate. The volume ratio of zeolite powder to the solution used was 1:10. The suspension was maintained at $60-70{ }^{\circ} \mathrm{C}$ for $24 \mathrm{~h}$. The slurry was repeatedly washed with distilled water and dried in air at $120^{\circ} \mathrm{C}$ for $2 \mathrm{~h}$ and then calcined at $500{ }^{\circ} \mathrm{C}$ for 2 $\mathrm{h}$ to obtain the ion exchanged zeolite $\mathrm{FA} / \mathrm{K}-\mathrm{X}$. Calcination at temperatures above 300 ${ }^{\circ} \mathrm{C}$ in air was undertaken to remove any organic additives and impurities [10]. Commercial zeolite Na-X used as a baseline for investigative studies was obtained from CWK, Bad Köstritz. 


\subsection{Catalyst characterization}

Characterization of fly ash applied has been presented elsewhere [19]. The synthesized fly ash based zeolite $\mathrm{Na}-\mathrm{X}$ catalysts (FA/ Na-X) and the ion exchanged fly ash based zeolite $\mathrm{X}(\mathrm{FA} / \mathrm{K}-\mathrm{X})$ were characterized using the techniques described below.

\subsection{1 $X$-rayfluorescence $(X R F)$}

Fresh fly ash was analysed for elemental composition using $X$ - ray fluorescence (XRF) using a Philips 1404 Wavelength Dispersive Spectrometer fitted with a Rh tube was used. The samples were oven-dried at $50{ }^{\circ} \mathrm{C}$ for $12 \mathrm{~h}$ to reduce their water content prior to analysis.

\subsubsection{X-ray powder diffraction (XRD)}

Commercial and synthesized catalyst zeolite FA/Na-X samples were analysed using a PANalytical X'Pert powder diffractometer with $\mathrm{Cu}-\mathrm{Ka}$ radiation. The samples were scanned from 4 to $60^{\circ}$ and the zeolitic phases were identified using X'Pert Highscore plus software by searching and matching the obtained patterns with the JCPDS (Joint committee of powder diffraction standards) database files.

\subsubsection{BET surface area}

The surface area and pore size determination was conducted by the application of a gravimetric nitrogen Brunauer-Emmett-Teller (N2-BET) surface analysis technique. The samples to be analysed was out gassed at $110{ }^{\circ} \mathrm{C}$ on the Flow Prep 060 using helium gas. The Micromeritics Tristar instrument was used with nitrogen as the analysis gas and determination was based on a 5 point procedure with 30 adsorption and 30 desorption points being measured.

\subsubsection{Fourier transformed infrared (FTIR) spectroscopy}

Fourier Transform Infrared spectroscopy (JASCO FT/IR-4100 spectrometer) was used to provide information about the structure of the zeolitic material and the samples were scanned in the range between 400 and $4000 \mathrm{~cm}^{-1}$.

\subsubsection{Scanning electron microscopy (SEM)}

The morphology of the catalyst materials were examined using a Hitachi X-65O scanning Electron Microanalyser equipped with a CDU lead detector. The instrument was operated at $25 \mathrm{kV}$. Prior to analysis, samples were mounted on aluminum pegs and coated with a thin film of gold to make them conductive.

\subsubsection{Base site strength test}

Hammett indicators were used to determine the base site strengths of the catalytic materials qualitatively according to the procedure by Xie et al. [5]. 


\subsection{Transesterification reaction}

$20 \mathrm{~g}$ of vegetable oil was weighed and placed in a $100 \mathrm{ml}$ two necked flask. The oil sample was heated to $60{ }^{\circ} \mathrm{C}$ by placing on a hot plate equipped with a mechanical stirrer (Heidolph MR 3001K). $10 \mathrm{ml}$ of methanol and $0.6 \mathrm{~g}$ of catalyst was weighed and added into the reactor. The reaction was carried out under reflux; a magnetic stirring rod was used for mixing the constituents at a stirring speed of $600 \mathrm{rpm}$. The reaction mixture was heated to $60-65{ }^{\circ} \mathrm{C}$ and was continuously stirred until completion of the reaction. After comple- tion of the methanolysis reaction, the mixture was centrifuged. The solid catalyst was recovered via filtration and the residual methanol was separated via rotary evaporation. The mixture was then placed in a separatory funnel and allowed to stand overnight to ensure that the separation of the methyl esters and the glycerol phase occurred completely. The glycerol phase was then separated and the methyl ester phase (biodiesel) was dried by adding $25 \%(\mathrm{w} / \mathrm{w}) \mathrm{Na}_{2} \mathrm{SO}_{4}$ based on the weight of the oil. The methyl ester samples are then placed in an ice bath until required for analysis. The methyl ester samples are then placed in an ice bath until required for analysis.

\section{Table 1}

Properties of sunflower oil.

\begin{tabular}{|l|l|}
\hline Property & Value \\
\hline Acid value $(\mathrm{mg} \mathrm{KOH} / \mathrm{g}$ oil $)$ & 0.89 \\
\hline Density $15^{\circ} \mathrm{C}\left(\mathrm{cm} 3 \mathrm{~g}^{-1}\right)$ & 9.2 \\
\hline Kinematic viscosity@ $15^{\circ} \mathrm{C}$ & 31 \\
\hline
\end{tabular}

\section{Results and discussion}

\subsection{Oil characterization}

The physical properties of sunflower oil used in this study such as density, viscosity and acid values are summarized in Table 1 . The low acid value of $0.89 \mathrm{mg} \mathrm{KOH} / \mathrm{g}$ oil recorded for the sunflower oil enabled the use of the Na-X and K-X as a base catalyst for the transesterification reactions. Density is the mass per unit volume of any liquid at a given temperature, this parameter is important in engine performance since fuel injection operates on a volume metering system. The kinematic viscosity value of 31 clearly falls into expected range.

\subsection{Thin layer chromatography result}

Fig. 1 reproduces a picture of the TLC conducted on the initial FAME samples 
obtained from the transesterification reactions with the commercial zeolite $\mathrm{Na}-\mathrm{X}$ (designated as A), synthesized zeolite catalyst FA/Na-X (designated as B) and the ion exchanged zeolite catalyst FA/K-X (designated as C) at fixed reaction conditions of 24 $\mathrm{h}$, methanol oil ratio $6: 1$, catalyst concentration $(3 \%, \mathrm{w} / \mathrm{w})$ and temperature of $65^{\circ} \mathrm{C}$.

The thin layer chromatographic (TLC) technique was undertaken in order to confirm the conversion of the triglyceride into methyl esters as reported by Babajide et al. [19]. This is a rapid analytical method that gives a qualitative indication of oil and methyl ester content in the mixture. Subsequent FAME content was determined using the EN 14103 standard method.

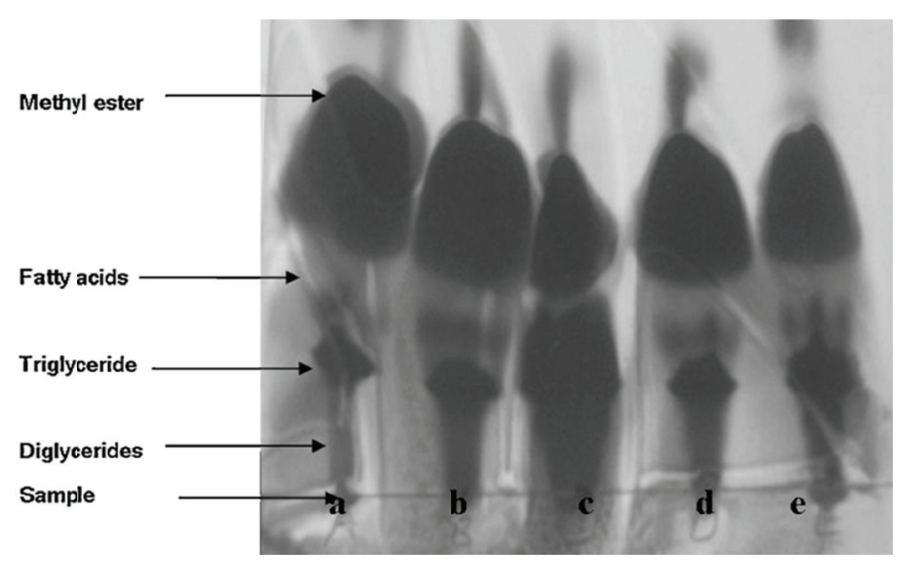

Fig. 1. TLC plate picture indicating the separation spots of FAME sample constituents (after transesterification reactions with zeolite materials) where (a) $\mathrm{FA} / \mathrm{K}-\mathrm{X}$ at $24 \mathrm{~h}$, (b) FA/K-X at $8 \mathrm{~h}$, (c) CM/Na-X at $8 \mathrm{~h}$, (d) FA/Na-X at $8 \mathrm{~h}$ and (e) $\mathrm{FA} / \mathrm{Na}-\mathrm{X}$ at $24 \mathrm{~h}$.

\subsection{Catalyst characterization}

The elemental composition of the South African Class F fly ash is given and the characterization results of the fly ash based zeolite catalysts are presented in this section. Commercial zeolite $\mathrm{Na}-\mathrm{X}$ was used as a baseline for comparison of the catalytic activity of the fly ash derived zeolite Na-X. The synthesized fly ash based zeolite Na-X was ion exchanged with potassium using potassium acetate as precursor to obtain the $\mathrm{FA} / \mathrm{K}-\mathrm{X}$ following the procedure described in the literature [10]. This was done in order to increase the base site strength required for improved transesterification reactions as reported in literature [15] as potassium-acetate exchanged commercial $\mathrm{Na}-\mathrm{X}$ zeolite has shown good performance in transesterification reactions [16]. The characterization results obtained are discussed in Sections 3.2.1-3.2.5. 


\subsubsection{X-rayfluorescence (XRF)}

The elemental chemical composition of the South African Class $\mathbf{F}$ fly ash determined by $\mathrm{XRF}$ is $\mathrm{SiO}_{2} 50.91 \%, \mathrm{Al}_{2} \mathrm{O}_{3} 30.91 \%, \mathrm{Na}_{2} \mathrm{O}$ 0.10\%, $\mathrm{CaO} 6.2 \%, \mathrm{Fe}_{2} \mathrm{O}_{3} 3.46 \%, \mathrm{MgO} 1.48 \%$, $\mathrm{TiO}_{2}$ 1.65\%, $\mathrm{MnO} 0.02 \%, \mathrm{~K}_{2} \mathrm{O} 0.60 \%$ and $\mathrm{P}_{2} \mathrm{O}_{5} 0.56 \%$ with an average $\mathrm{SiO}_{2} / \mathrm{Al}_{2} \mathrm{O}_{3}$ ratio of 1.65. This is a typical composition of fly ash from combustion of bituminous coal from South Africa [22].

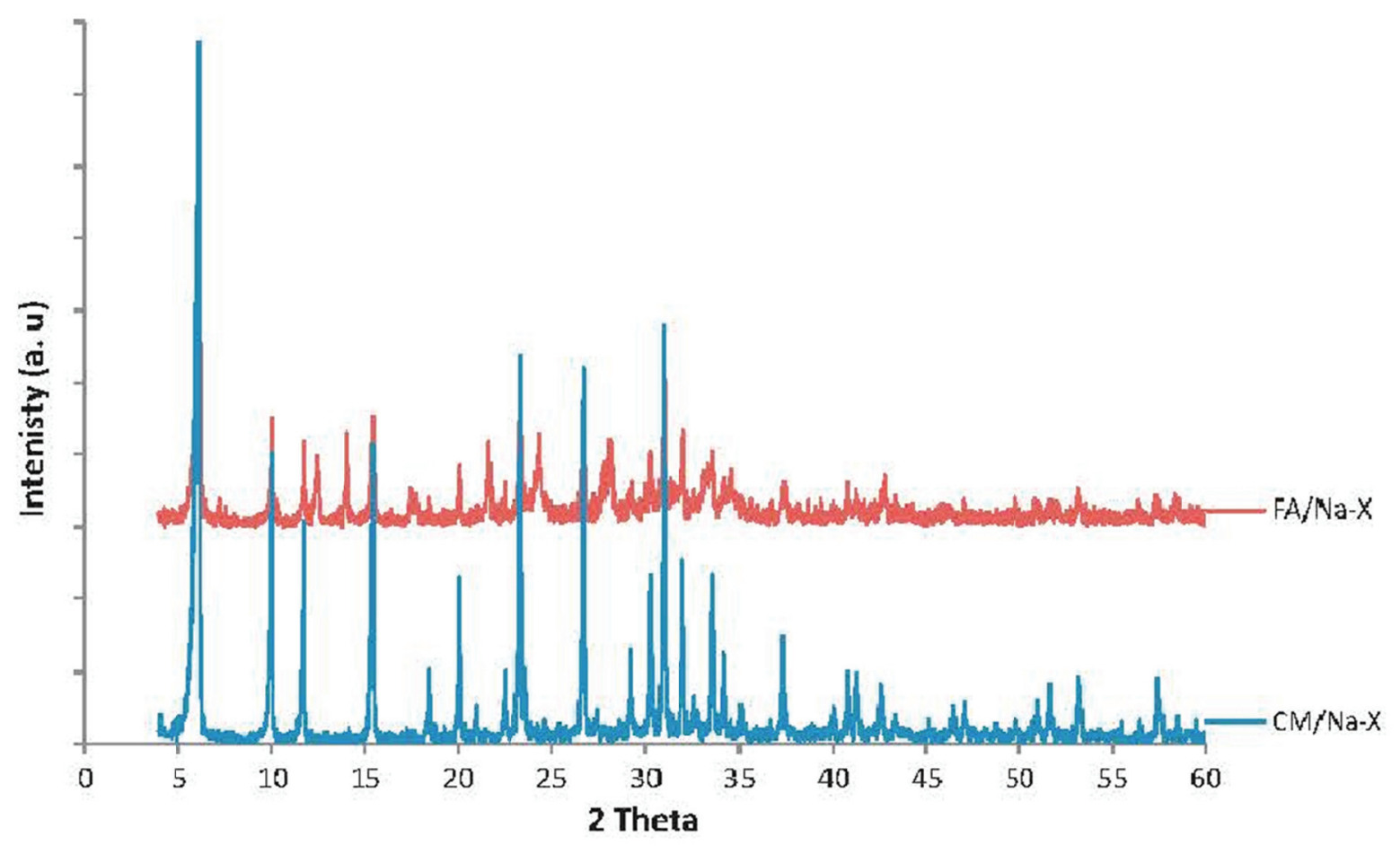

D patterns of the commercial zeolite catalyst (CM/Na-X) and synthesized fly ash based zeolite Na-X catalyst (FA/Na-X).

2 Theta

Fig. 2. XRD patterns of the commercial zeolite catalyst (CM/Na-X) and synthesized fly ash based zeolite Na-X catalyst (FA/Na-X).

\section{Table 2}

BET surface area measurements of the catalyst materials. Sample BET area $\left(\mathrm{m}^{2} \mathrm{~g}^{-1}\right) \quad$ Pore volume $\left(\mathrm{cm} 3 \mathrm{~g}^{-1}\right)$

\begin{tabular}{lll}
\hline FAa & 2 & 0.014 \\
$\mathrm{CM} / \mathrm{NaX}$ & 802 & 3.62 \\
$\mathrm{FA} / \mathrm{NaX}$ & $32 \mathrm{O}$ & 1.40 \\
FA/KX & 257 & 1.28
\end{tabular}

a South African Class F fly ash. 
The XRD patterns of the commercial zeolite catalyst (CM/Na-X) and synthesized Arnot fly ash based zeolite $\mathrm{Na}-\mathrm{X}$ zeolite catalyst (FA/Na-X) are shown in Fig. 2.

Normally zeolite $\mathrm{X}$ which has the ratio of $\mathrm{Si} / \mathrm{Al}$ ranging from 2 to 3 [11]. Using fly ash as the feed stock to synthesize zeolites, one can obtain different types of zeolites depending on the composition of the synthesis mixture [9]. In the case of the synthesis of zeolite $\mathrm{Na}-\mathrm{X}$ from the South African fly ash, a low $\mathrm{Si} / \mathrm{Al}$ ratio had been found to preferentially result in the zeolite $\mathrm{Na}-\mathrm{X}$ [24]. The XRD patterns of the $\mathrm{CM} / \mathrm{Na}-\mathrm{X}$ and FA/Na-X show similar diffraction peaks except for an additional contaminant phase which results in reflections at $2 \mathrm{e}=12^{\circ}, 14^{\circ}$ and $24^{\circ}$ in the FA/Na-X sample. Reports from literature state that faujasite zeolites $\mathrm{X}$ and $\mathrm{Y}$ are thermally stable [25] which make them potentially attractive as catalysts for transesterification reactions requiring moderate to elevated temperatures.

\subsubsection{BET surface area measurement}

The surface areas of the CM/Na-X, FA/Na-X and FA/K-X deter- mined by BET measurements are shown in Table 2.

The BET surface area and the pore volume of the commercial and fly ash based zeolite Na-X were determined. The surface areas values of the commercial zeolite used in this study were found to be higher than that of the fly ash based zeolite as shown in Table 2. The difference can be attributed to the degree of purity as highlighted by the XRD analysis reported in Section 3.2.1. Comparing the surface area of the FA/Na-X with its ion exchanged counterpart, it can be seen that the fly ash based zeolite $\mathrm{Na}-\mathrm{X}$ exhibited a higher surface area value of $320 \mathrm{~m}^{2} \mathrm{~g}^{-1}$. The ion exchanged FA/K-X gave a lower surface area value of $257 \mathrm{~m}^{2} \mathrm{~g}^{-1}$ on the other hand as a result of a relative bigger size of $\mathrm{K}^{+}$compared to $\mathrm{Na}^{+}$. This gives an indication that the ion exchange with $\mathrm{K}^{+}$had a pore blocking effect. The relatively high surface area for both the FA/Na-X and FA/K-X compared to fly ash itself $\left(3 \mathrm{~m}^{2} \mathrm{~g}^{-1}\right)$ [24] presents an advantage on the use of these zeolitic materials, which presumably would anchor and enable catalytic reactions of the large triglyceride molecules [26]. This is desirable to promote conversion of triglycerides into methyl esters during the transesterification reactions in biodiesel synthe- sis. The surface area of the zeolite FA/Na-X reported in this study is comparatively higher than the surface area values of $200 \mathrm{~m}^{2} \mathrm{~g}^{-1}$ [12] reported in literature for zeolite $\mathrm{Na}-\mathrm{X}$ synthesized from coal fly ash from other sources. It was expected that this characteristic would present a higher potential in increased catalytic efficiency during the transesterification studies. 
The FTIR spectra of the commercial zeolite catalyst (CM/Na-X) and the South African Class F fly ash zeolite catalyst (FA/Na-X) are presented in Fig. 3.

IR analysis of the FA/ $\mathrm{NaX}$ obtained through the conventional hydrothermal synthesis process shows all the characteristic bands for zeolite $\mathrm{Na}-\mathrm{X}$ and compares well with the bands obtained from its commercial counterpart (Fig. 3). A summary of vibration bands of zeolites was reported by Breck [27]. The strongest vibration at 950 $\mathrm{cm}^{-1}$ is assigned to a $\mathrm{T}-\mathrm{O}$ stretch and the stretching modes involving mainly the tetrahedral atoms are assigned in the region

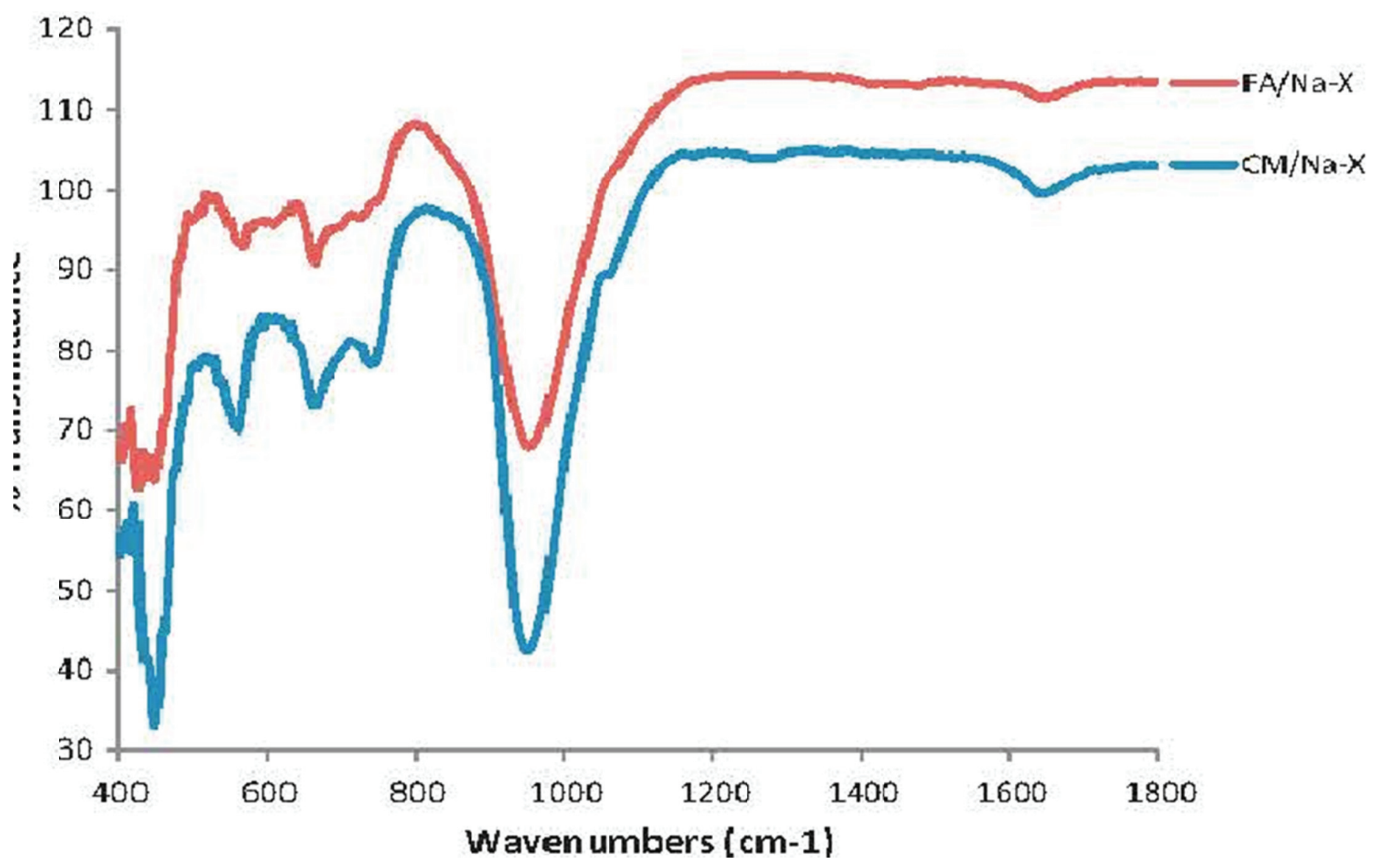




\section{Wavenumbers (cm-1)}

Fig. 3. IR spectra of the commercial zeolite catalyst (CM/Na-X) and the synthesized fly ash based zeolite $\mathrm{Na}-\mathrm{X}$ catalyst (FA/Na-X).

of 740 and $620 \mathrm{~cm}^{-1}$. Generally, stretching modes are sensitive to the $\mathrm{Si}-\mathrm{Al}$ composition of the framework which may shift to a lower frequency with increasing number of tetrahedral aluminium atoms, resulting in the occurrence of the second group of frequencies that are sensitive to the linkages [28]. The vibration bands of secondary building units of zeolite $\mathrm{Na}-\mathrm{X}$ are reported to occur in the regions of $600-500$ and $430-300 \mathrm{~cm}^{-1}$ [11]. The band in the $600-500 \mathrm{~cm}^{-1}$ region can be related to the presence of a double ring in the frame- work structures and is observed in all the zeolite structures that contain the double 4 and double 6-rings [28].

\subsubsection{Scanning electron microscopy (SEM)}

Morphologies of South African Class F fly ash, commercial zeolite $\mathrm{Na}-\mathrm{X}$ and the South African Class F fly ash zeolite FA/Na-X catalysts are shown in Fig. 4.

Scanning Electron Microscopy (SEM) was used to determine the morphology and particle size of the zeolite crystals. The SEM micrograph of the raw fly ash (Fig. 4a) shows the initial morphology of the starting material before zeolitization. Majority of the fly ash particles were spherical in shape with a few that were irregularly shaped. The morphology of the commercial Na-X (Fig. 4b) was found to contain the typical octahedral crystal formation of faujasite zeolites [25]. Fig. 4c shows a yarn rolled ball like unique morphology with irregular crystals of the faujasite phase of the fly ash zeolite $\mathrm{FA} / \mathrm{Na}-\mathrm{X}$ after the hydrothermal synthesis process. The morphology of fly ash zeolite FA/Na-X after ion exchange, as expected, did not show any significant difference (Fig. 4d). The differences observed in the surface areas (Table 2) were due to the differences in the morphology. The observed hierarchical morphology of the Na-X crystals induces mesoporosity which thus leads to an increase in the external surface area. This unique morphology has over the recent years been of intense interest [29] and latest studies by $\mathrm{Na}$ et al. [30] have suggested that hierarchical zeolites possess attractive applications due to their large external surface area which exposes more active sites that result in increased efficiency.

\subsubsection{Base site strength test}

The base site strength of the fly ash zeolite FA/Na-X and FA/K-X catalysts is presented in Table 3. 
The ion exchanged fly ash zeolite FA/K-X catalyst material changed the colour of 2,4-dinitroaniline $(\mathrm{H}=15)$ from yellow to mauve but did not convert 4 -nitroaniline $(\mathrm{H}=18.4)$ to its conjugate base form and therefore its strong base strength could be indicated as $15<\mathrm{H}<18.4$. On the other hand, the fly ash zeolite FA/Na-X catalyst did not exhibit the same strong basic strength, as it gave a medium base strength of 9.3 $<\mathrm{H}<15$.0. Categories of base materials have been discussed by Tanabe [31].
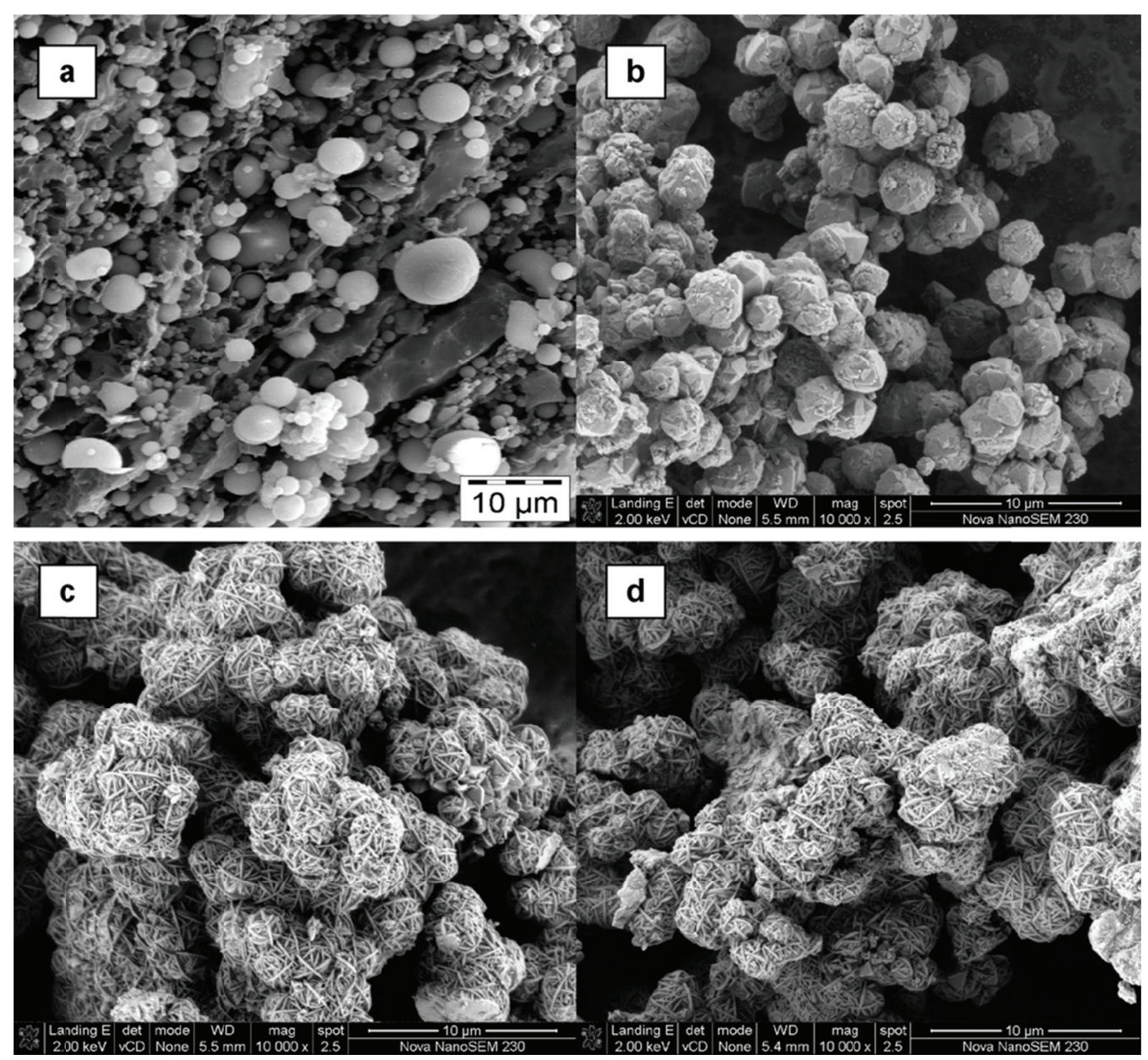

Fig. 4. SEM micrograph of (a) South African class $F$ fly ash, (b) commercial zeolite catalyst (CM/Na-X), (c) synthesized fly ash based zeolite Na-X catalyst (FA/Na-X), and (d) ion exchanged fly ash based zeolite catalyst (FA/K-X).

\subsection{Catalytic activity of the ash based zeolite $\mathrm{Na}-\mathrm{X}$ and $\mathrm{K}-\mathrm{X}$ catalysts}

The catalytic activities of the commercial NaX, FA/Na-X and FA/K-X catalysts were studied in the transesterification reactions of sunflower oil with methanol. Batch reactions were conducted at two different contact times under identical conditions. Initially a reaction time of $8 \mathrm{~h}$ was applied and then a reaction time of $24 \mathrm{~h}$ (methanol oil ratio $6: 1$, catalyst $-3 \%(\mathrm{w} / \mathrm{w})$ of oil and temperature 
of $\left.65^{\circ} \mathrm{C}\right)$. The results are presented in Fig. 5 .

The catalytic activities of all the catalysts used in the transes- terification reactions, as shown in Fig. 6, reveal ester yields of 17.5, 56 and 83.53\% which were obtained for the $\mathrm{CM} / \mathrm{Na}-\mathrm{X}, \mathrm{FA} / \mathrm{N}-\mathrm{aX}$ and FA/K-X zeolite catalysts respectively at a reaction time of $8 \mathrm{~h}$. At a reaction time of $24 \mathrm{~h}$, whilst other reaction conditions remained constant, ester yields of $10.24,65.35$ and $85.51 \%$ were obtained with the use of the CM/Na-X, FA/Na-X and FA/K-X zeolite cata- lysts respectively. The results show slightly higher methyl ester yields at a reaction time of $24 \mathrm{~h}$ with the exception of the $\mathrm{CM} / \mathrm{Na}-$ $\mathrm{X}$ recording lower FAME value of $10.2 \%$ at the longer reaction time. The catalytic activity of the ion exchanged fly ash zeolite FA/ K-X catalyst was clearly higher than the CM/Na-X and the FA/Na-X cat- alysts for both contact times ( 8 and $24 \mathrm{~h}$ ). This improved catalytic activity after ion exchanging the $\mathrm{Na}-\mathrm{X}$ to the $\mathrm{K}^{+}$form was probably

\section{Table 3}

Basic strength test for the catalyst materials.

\begin{tabular}{|l|l|}
\hline Catalyst material & Basic strength $(\mathrm{H})$ \\
\hline FA/Na-X & $9.3<\mathrm{H}_{-}<15.0$ \\
\hline FA/K-X & $15.0<\mathrm{H}_{-}<18.4$ \\
\hline
\end{tabular}




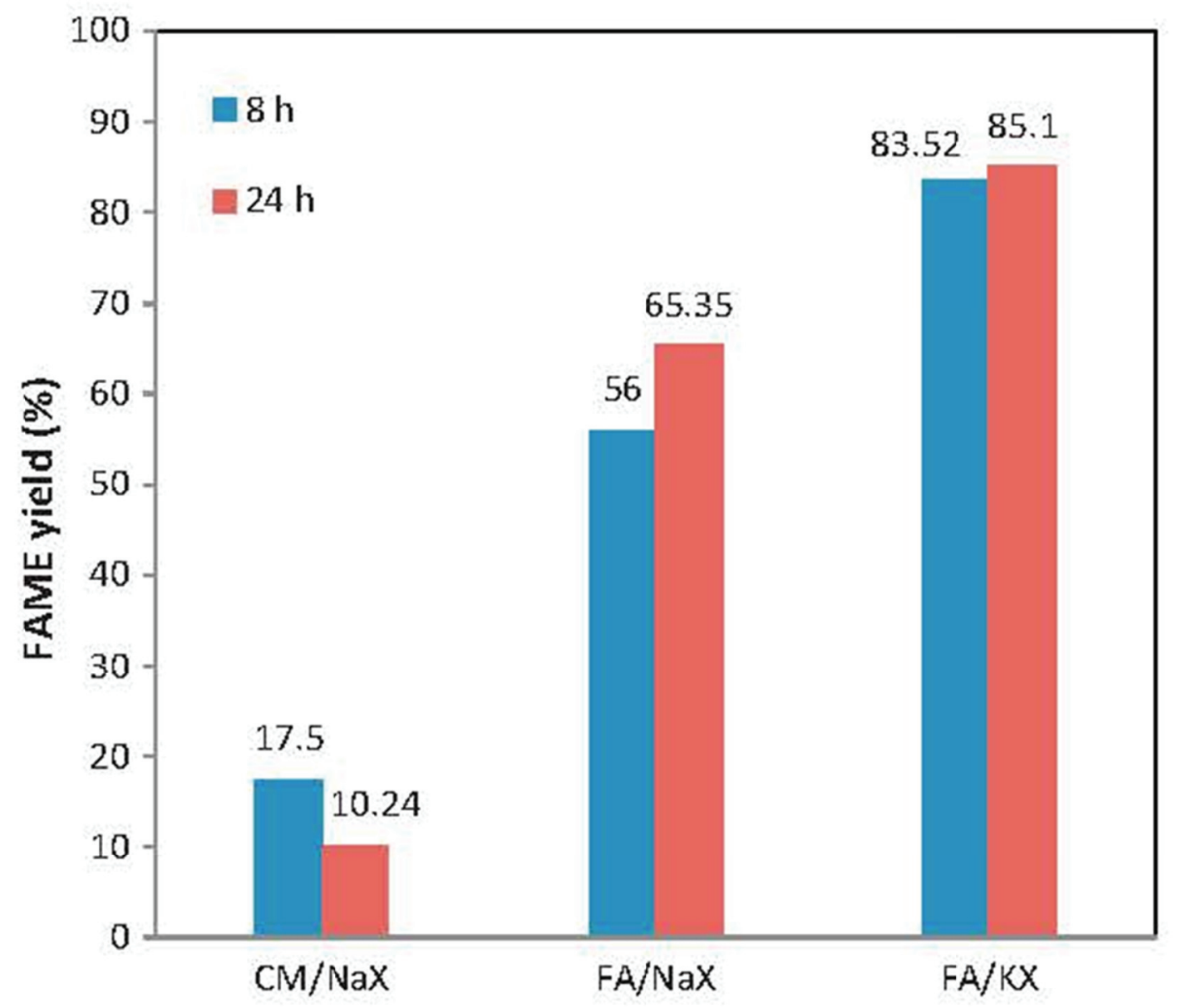

Fig. 5. Catalytic activity of the different zeolite catalysts under reaction conditions, methanol oil ratio $6: 1$, catalyst ( $3 \%, w / w$ of oil) and temperature of $65^{\circ} \mathrm{C}$ at 8 and $24 \mathrm{~h}$ respectively. 


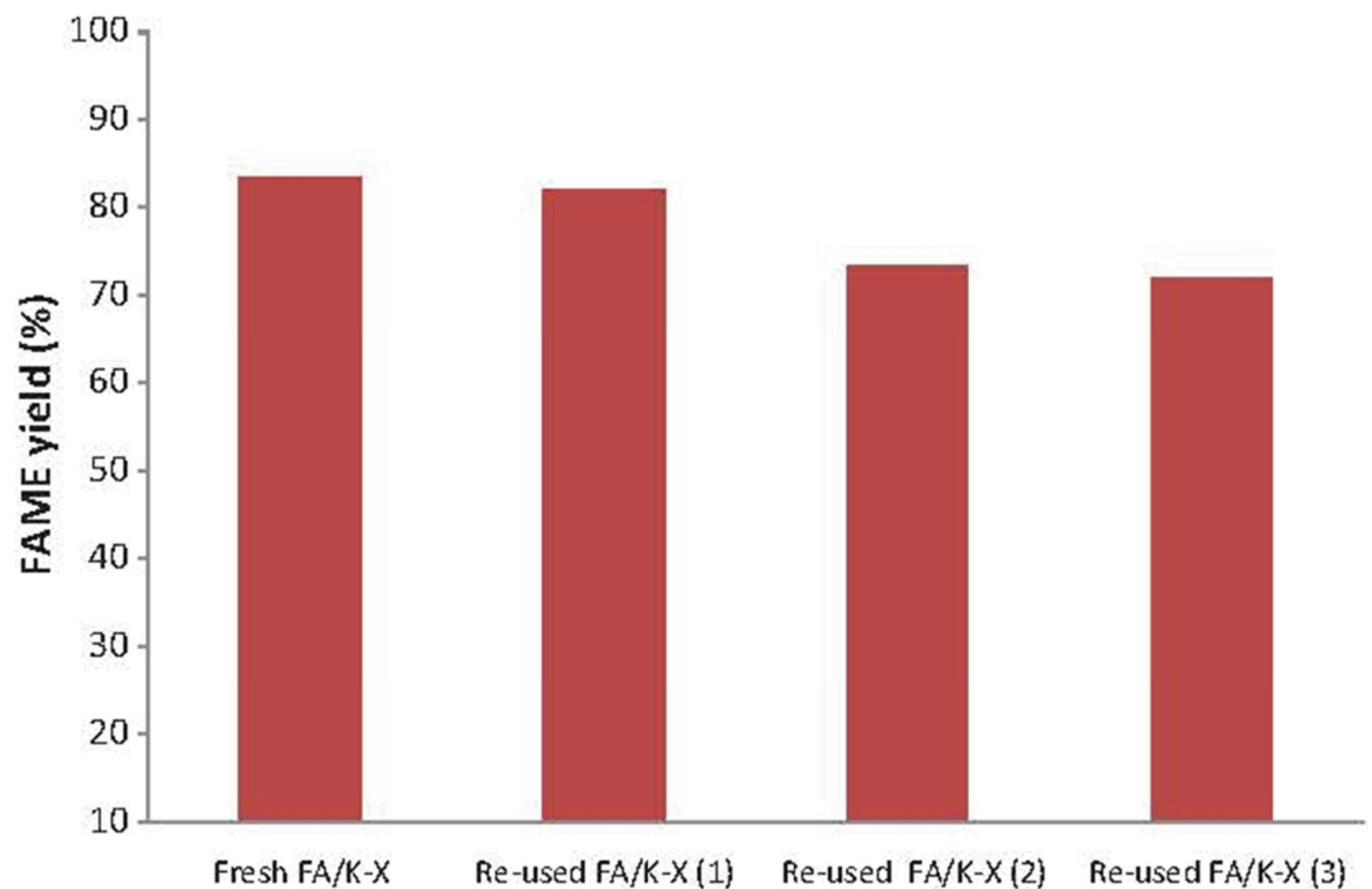

Fig. 6. Deactivation studies to test reusability of the zeolite FA/K-X catalyst.

due to the presence of second-order intercrystalline pores which reduce the diffusional constraint experienced when using the zeolite $\mathrm{X}$ with the conventional octahedral crystals in the $\mathrm{CM} / \mathrm{Na}-\mathrm{X}$ ). The base strength of the $\mathrm{K}^{+}$exchanged zeolite which increases correspondingly with the electropositive nature of the exchanged cation can also be attributed to this observation. It has been shown that the conversion to methyl ester over $\mathrm{Na}-\mathrm{X}$ faujasite zeolite that was ion exchanged with more electropositive cations was higher than the parent zeolite [15,16,32]. The transesterification activities of the FA/Na-X and FA/K-X also followed the order of basic strength as determined by the Hammett titration illustrating a correlation between the intermediate electronegativity of both catalysts with the methyl ester yields. In the case of basic catalysts like $\mathrm{NaOH}$ or $\mathrm{KOH}$, when they are mixed with methanol in transesterification reactions, the actual catalyst (the alkoxide group) attacks the carbonyl carbon atom of the triglyceride molecule to convert triglycerides to their respective methyl esters. A related mechanism is operational in the case of the heterogeneous catalyst such as a basic zeolite [33]. As in this case also, the formed catalytic species is a homogeneous alkoxide as shown in Scheme 1 below.

According to reports in literature, the use of different types of faujasite zeolite catalysts used in transesterification reactions has reported low conversions $[15,16,34]$ in comparison to the value reported in this work. Different zeolite for catalysis in biodiesel transesterification reactions at different reaction conditions 
have also been reported [26]. The finding in this study presents superior results. The relatively higher FAME yields derived in this study can be related to the South African Class $\mathrm{F}$ fly ash raw material used in the zeolite synthesis. The elemental composition of the fly ash as previously mentioned was shown to be rich in $\mathrm{SiO}_{2}$, $\mathrm{Al}_{2} \mathrm{O}_{3}$ and $\mathrm{CaO}$ content and the higher surface area of the fly ash based zeolite $\mathrm{Na}-\mathrm{X}$ formed using this source of fly ash as observed (Table 2) might contribute to this phenomenon. Broges et al. [16] recently reported a 80.8\% FAME yield from a potassium acetate loaded zeolite $\mathrm{Na}-\mathrm{X}$ at high reaction temperature of $155^{\circ} \mathrm{C}, 48: 1$ methanol to oil ratio and a $6 \%(\mathrm{w} / \mathrm{w})$ catalyst amount whilst Noiroj et al. [35] and Xie and Huang [32] report the use of $\mathrm{KOH} / \mathrm{Na}-\mathrm{Y}$ and $\mathrm{KOH}-$ promoted Na-X zeolite catalysts to achieve a biodiesel yield of $91 \%$ and a $85 \%$ conversion to methyl esters in 8 $\mathrm{h}$ at $66^{\circ} \mathrm{C}$ respectively although

Where $\mathrm{M}$ is alkali metal ( $\mathrm{Na}$ or $\mathrm{K}$ ) and $\mathrm{R}$ is alkyl group

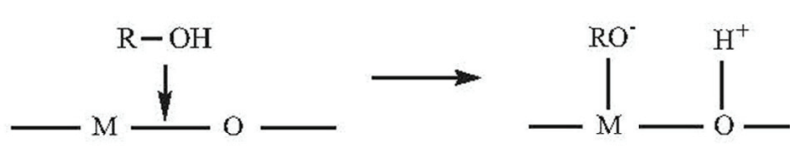

Where $\mathrm{M}$ is alkali metal ( $\mathrm{Na}$ or $\mathrm{K}$ ) and $\mathrm{R}$ is alkyl group

Scheme 1.

at higher methanol:oil ratios of 10:1. In this study, a methanoll:oil ratio of 6:1 was used and found sufficient to propel the transesterification reaction as if the methanol:oil ratio is high; a surplus of the methanol molecules would cause a flooding of available sites [34]. In other transesterification studies conducted with basic zeolites, the incorporation of occluded $\mathrm{NaOx}$ species in zeolite-X significantly increased the basic strength and concentration, which ultimately enhanced the transesterification activity and increased the yield of methyl ester from soybean oil from 22.7 to $94.2 \%$ when $\mathrm{NaOx} / \mathrm{NaX}$ replaced $\mathrm{K}-\mathrm{X}$ as a catalyst [18]. Although this study used a long operation time $(24 \mathrm{~h})$ and the reaction temperature at $120^{\circ} \mathrm{C}$, obtained at a methanol/oil molar ratio of 6:1, which is similar to the results reported here for heterogeneous biodiesel synthesis. The reaction temperature employed in this study was found suit- able for the transesterification reactions [36]. More investigations to determine the optimum reaction conditions and the reusability of the ion exchanged Arnot fly ash zeolite $\mathrm{NaX}$ catalyst (FA/KX) are currently ongoing.

\subsection{Deactivation tests}

Deactivation studies were done to test the reusability of the zeolite FA/K-X catalyst during the biodiesel synthesis from sunflower oil. The catalyst was filtered and reused in the transesterification reactions after being washed with methanol to eliminate the glycerol.

The results presented in Fig. 6 show that there is potential to reuse the catalyst up to three times. 


\section{Conclusion}

Novel zeolite-Na-X synthesized from South African class F fly ash was ion exchanged with potassium using potassium acetate as precursor to obtain the fly ash based FA/K-X zeolite catalyst. The inclusion of potassium into the pore cavity of the fly ash zeolite- Na-X through ion exchange increased the basicity of the zeolite for the transesterification reactions. The South African class F fly ash derived zeolite catalysts were found to be active in the transesterification of sunflower oil with methanol to produce fatty acid methyl esters (biodiesel). Furthermore, the FA/K-X presented higher catalytic activity, mostly as a result of the anchoring of the alkali metal (K) through ion exchange inside the zeolite pores resulting in a higher conversion of methyl esters. The fly ash derived zeolite $\mathrm{Na}-\mathrm{X}$ and $\mathrm{K}-\mathrm{X}$ exhibited relatively high surface areas showing adequate transformation of the fly ash into zeolite. The overall results indicated that a high quality FAME yield of 83.53 and $85.5 \%$ was obtained from the transesterification reactions at reaction times of 8 and $24 \mathrm{~h}$ respectively using the ion-exchanged South African class F fly ash zeolite catalyst (FA/KX) at reaction conditions of methanol:oil ratio of $6: 1$, catalyst $-3 \%(\mathrm{w} / \mathrm{w})$ of oil at a reaction temperature of $65{ }^{\circ} \mathrm{C}$. Thus South African class $\mathrm{F}$ fly ash transformed into a zeolite $\mathrm{Na}-\mathrm{X}$ phase and exchanged with $\mathrm{K}$ proved to be suitable for use as a heterogeneous catalyst in biodiesel synthesis under less rigorous conditions than previously reported.

\section{Acknowledgement}

The authors wish to thank the National Research Foundation, South Africa for financial support.

\section{References}

[1] R. Luque, L. Herrero-Davila, J.M. Campelo, J.H. Clark, J.M. Hidalgo, D. Luna, J.M. Marinas, A.A. Romero, Energy Environental Science 1 (2008) 542-564.

[2] O. Babajide, L. Petrik, B. Amigun, F. Ameer, Energies 3 (2010) 1691-1703.

[3] F. Ma, M.A. Hanna, Bioresource Technology 70 (1999) 1-15.

[4] L. Bournay, D. Cassanave, B. Delfort, G. Hillion, J.A. Chadorge, Catalysis Today 106 (2005) 190-192.

[5] W. Xie, H. Peng, L. Chen, Applied Catalysis A 300 (2006) 67-74.

[6] K.S. Hui, K.N. Hui, S.K. Lee, World Academy of Science, Engineering and Technology 53 (2009) 174-184. 
[7] K. Ojha, N.C. Pradhan, A.N. Samanta, Bulletin of Materials Science 7 (2004) 555-564.

[8] M. Inada, H. Tsujimoto, Y. Eguchi, N. Enomoto, J. Hojo, Fuel 84 (2005) $1482-1486$.

[9] X. Querol, N. Moreno, J.C. Uman, A. Alastuey, E. Herna`indez, A. Lo`ipez-Soler, F. Plana, The International Journal of Coal Geology 5o (2002) 413-423.

[10] K.M. Lee, Y.M. Jo, Journal of Material Cycles and Waste Management 12 (2010) 212-219.

[11] S.S. Lee, A.M. Rideau, L.B. McGown, Journal of Physical Chemistry 100 (1996) $5880-5887$.

[12] H. Tanaka, S. Furusawa, R. Hino, Journal of Materials Synthesis and Processing 10 (3) (2002) 143-148.

[13] B. Prasad, R.J.G. Mortimer, Water, Air, and Soil Pollution (2009) 676-680.

[14] H.L. Chang, W.H. Shih, Industrial and Engineering Chemistry Research 39 (2000) 4185-4191.

[15] G.J. Suppes, K. Bockwinkel, S. Lucas, J.B. Botts, M.H. Mason, A.J. Heppert, Journal of the American Oil Chemists Society 78 (2001) 139-149.

[16] M.E. Borges, A. Brito, A. Hernández, L. Diaz, International Journal of Chemical Reactor Engineering 9 (2011) 1-22.

[17] D.W. Lee, Y.M. Park, K.Y. Lee, Catalysis Surveys from Asia 13 (2009) 63-77.

[18] M. Di Serio, R. Tesser, L. Pengmei, E. Santacesaria, Energy and Fuels 22 (2008) 207-217.

[19] O. Babajide, L. Petrik, N. Musyoka, B. Amigun, F. Ameer, Petroleum and Coal 2 (4) (2010) 261-272.

[20] W. Xue, Y.-C. Zhou, B.-A. Song, X. Shi, J. Wang, S.-T. Yin, D.-Y. Hu, L.-H. Jin, S. Yang, Natural Science 1 (2009) 55-62.

[21] A. Carrero, G. Vicente, R. Rodríguez, M. Linares, G.L. Del Peso, Catalysis Today 167 (2011) 148-153.

[22] M.W. Gitari, L.F. Petrik, D.L. Key, E. Iwuoha, C. Okujeni, Journal of Environment Science and Health 41 (2006) 1729-1747. 
[23] N.M. Musyoka, L. Petrik, E. Hums, Pending Patent, University of the Western Cape, South Africa, 2012.

[24] N.M. Musyoka, Unpublished MSc Thesis, University of the Western Cape, South Africa (2009).

[25] H.J. Lee, Y.M. Kim, O.S. Kweon, I.J. Kima, Journal of the European Ceramic Society 27 (2007) 561-564.

[26] A.K. Endalew, Y. Kiros, Z. Rolando, Biomass and Bioenergy 35 (2011) 3787-3809.

[27] D.W. Breck, Zeolite Molecular Sieves, Structure, Chemistry and Uses, John Wiley \& Sons, New York, 1974.

[28] E.M. Flanigien, in: H. van Bekkum, E.M. Flanigen, J.C. Jansen (Eds.), Introduction to Zeolite Science and Practice, Elsevier, Amsterdam, 1991

[29] K. Möller, T. Bein, Science 333 (2011) 297.

[30] K. Na, C. Jo, J. Kim, K. Cho, J. Jung, Y. Seo, R.J. Messinger, B.F. Chmelka, R. Ryoo, Science 333 (2011) 328-332.

[31] K. Tanabe, in: B. Imelik, C. Nacceche, G. Condurier, Y. Bentaarti, J.C. Vedrine (Eds.), Catalysis by Acids and Bases, Elsevier, Amsterdam, 1985, p. 1.

[32] W. Xie, X. Huang, Catalysis Letters 107 (2006) 53-59.

[33] E. Lotero, J.G. Goodwin, D.A. Bruce, K. Suwannakarn, Y. Liu, D.E. Lopez, Catalysis 19 (2006) 41-84.

[34] K. Noiroj, P. Intarapong, A. Luengnaruemitchai, S. Jai-In, Renewable Energy 34 (2009) 1145-1150.

[35] Q. Shu, Q. Zhang, G. Xu, J. Wang, Food and Bioprocess Technology 87 (2009) 164-170.

[36] M.J. Ramos, A. Casas, L. Rodriguez, R. Romero, A. Perez, Applied Catalysis AGeneral 346 (2008) 79-85. 